\title{
COMPREHENSIVE STUDY ON EFFECTIVENESS AND ADVANTAGES OF DEXMEDETOMIDINE AND ESMOLOL IN CONTROLLED HYPOTENSION FOR FUNCTIONAL ENDOSCOPIC SINUS SURGERY
}

\author{
M. Ravikumar ${ }^{1}$, P. Shanmugasundaram ${ }^{2}$ \\ ${ }_{1}^{1}$ Assistant Professor, Department of Anaesthesia, Government Chengalpattu Medical College. \\ ${ }^{2}$ Associate Professor, Department of Anaesthesia, Government Chengalpattu Medical College.
}

ABSTRACT

\section{BACKGROUND}

Functional endoscopic sinus surgeries are performed either under local anaesthesia or under general anaesthesia. In patients with extensive disease, multiple sinuses involvement, it is preferable to do the surgery under general anaesthesia. Nose is a well vascularised area, bleeding during the surgery is the main problem. Minimal bleeding may obstruct the vision via the endoscope. Many methods have been used to create a bloodless field like topical vasoconstrictor agents like adrenaline, xylometazoline, preoperative steroids, head-up position, alpha and beta blockers. Controlled hypotension using sodium nitroprusside infusion, nitroglycerin infusion also used to create bloodless field. We designed the study to assess the effectiveness of Esmolol and Dexmedetomidine for FESS procedures.

The aim of the study was to compare the effectiveness and advantages of using dexmedetomidine and esmolol in controlled hypotension for functional endoscopic sinus surgery.

\section{MATERIALS AND METHODS}

The study was conducted in the Department of Anaesthesiology, Govt. Chengalpattu Medical College, Tamilnadu, in fifty patients of ASA physical status I posted for functional endoscopic sinus surgery. Patient belonged to age groups 20 - 50 years. All patients were premedicated with Inj. Glycopyrrolate $4 \mathrm{mcg} / \mathrm{kg}$ intramuscularly 45 minutes before surgery. Inj. Midazolam $0.03 \mathrm{mg} / \mathrm{kg}$, Inj. Fentanyl $2 \mathrm{mcg} / \mathrm{kg}$ intravenously given before starting the arterial line. In Group E, patients were given a loading dose of Esmolol $0.5 \mathrm{mg} / \mathrm{kg}$ over $1 \mathrm{~min}$ followed by infusion of $0.3-0.8 \mathrm{mg} / \mathrm{kg} /$ hour before induction. In Group D, patients were given a loading dose of dexmedetomidine at $1 \mathrm{mcg} / \mathrm{kg}$ over 10 minutes followed by infusion at the rate $0.3-0.8 \mathrm{mcg} / \mathrm{kg} / \mathrm{hour}$ before induction. In both the groups, infusion doses were titrated to obtain a mean arterial pressure between $60-65 \mathrm{mmHg}$. The dose of propofol required for induction was noted. Infusion of the study drugs was stopped 10 minutes before the end of the surgery. Haemodynamic monitoring, quality of surgical field, emergence time, post anaesthesia recovery score and sedation score were noted.

Statistical Analysis- The data was analysed by statistical software SPSS 17.0 and XLSTAT 2013. Students' " $t$ " test was used to find out the continuous data in between two groups. A pilot study was first conducted to define the population and to decide on the inclusion and exclusion criteria, and the target population of 25 subjects in each group was decided. Fifty patients of ASA Physical status I and II undergoing FESS were included in the study. Sample size calculation done before the start of the study. The sample size was calculated to be 52 (we have taken 25 in each group) using OpenEpi software version 3.01 taking into account mean recovery characteristics, sedation score (time to modified Aldrete score $>9$ mins. of $9.4 \pm 2.5$ in dexmed group and $7.5 \pm 2.3$ in esmolol group from the study done by Shams $\mathrm{T}$ et al, $95 \%$ confidence interval and $80 \%$ power.

\section{RESULTS}

The two groups were comparable in their baseline characteristics like age, sex and weight. The dose of Propofol required was low in Group D. Heart rate and blood pressure at the end of surgery and after extubation were significantly lower in Group D than Group E. Quality of surgical field is comparable in both the groups. Post-operative recovery score and sedation score were higher in Group D than in Group E.

\section{CONCLUSION}

The use of dexmedetomidine for controlled hypotension for functional endoscopic sinus surgery has the additional advantage of sedative and anaesthetic sparing effect than esmolol.

\section{KEYWORDS}

Dexmedetomidine, Esmolol, Controlled Hypotension, FESS.

HOW TO CITE THIS ARTICLE: Ravikumar M, Shanmugasundaram P. Comprehensive study on effectiveness and advantages of dexmedetomidine and esmolol in controlled hypotension for functional endoscopic sinus surgery. J. Evolution Med. Dent. Sci 2017;6(34):2789-2793, DOI: 10.14260/Jemds/2017/601

Financial or Other, Competing Interest: None.

Submission 06-04-2017, Peer Review 19-04-2017,

Acceptance 21-04-2017, Published 27-04-2017.

Corresponding Author:

Dr. M. Ravikumar,

No. 140B, $3^{\text {rd }}$ Main Road,

Anna Nagar,

Chengalpattu, Kancheepuram -603001.

E-mail: drravikumarcpt@gmail.com

DOI: $10.14260 /$ jemds $/ 2017 / 601$

\section{BACKGROUND}

Functional endoscopic surgery is a minimally invasive technique to drain the sinus cavities. Endoscopic sinus surgeries are most commonly performed in inflammatory and infectious sinus diseases. ${ }^{1}$ Maintenance of the bloodless field is very essential to improve the visualisation. Controlled hypotension is a method employed in functional endoscopic sinus surgery, middle ear surgery and also in spine surgeries ${ }^{2}$ to reduce the blood loss and to improve visibility of the surgical field and also helps in reducing blood transfusion 
during surgery. Various methods have been used to create a bloodless field like topical vasoconstrictor agents like adrenaline, xylometazoline, preoperative steroids, head-up position, alpha and beta blockers and vasodilators like hydralazine. ${ }^{3}$ Comparative studies have been published using esmolol, remifentanil in middle ear surgeries. Esmolol is an ultra-shortacting selective beta blocker. Beta blockers produce hypotension by decreasing the myocardial contractility and cardiac output, thereby improves the surgical field quality. ${ }^{4}$ Dexmedetomidine is a selective alpha-2 agonist, which has sedative and analgesic properties. Presynaptic activation of alpha-2 receptors inhibits norepinephrine release. Postsynaptic activation of alpha-2 receptors in CNS inhibits sympathetic activity and thus reduces blood pressure and heart rate. 5 The sedative properties of dexmedetomidine are mediated through action on postsynaptic alpha- 2 receptors in locus coeruleus in brain and spinal cord.

\section{MATERIALS AND METHODS}

This was a prospective, double-blind randomised comparative study in Govt. Chengalpattu Medical College after obtaining permission from Institutional Ethical Committee. A target population of 25 subjects in each group was decided. Fifty patients of ASA physical status I posted for functional endoscopic sinus surgery were included in the study. The patients belonged to the age groups 20 - 50 years.

\section{Inclusion Criteria}

1. Patients of ASA physical status I.

2. Age groups 20 - 50 years.

3. Patients posted for elective FESS.

\section{Exclusion Criteria}

1. Patients with ischaemic heart disease.

2. Patients with diabetes and hypertension.

3. Patients with liver and renal dysfunction.

4. Patients with bleeding diathesis.

5. Patients coming for recurrent sinus surgery.

\section{Materials Required}

1. 18-G IV cannulae.

2. 20-G radial artery cannula.

3. 50 cc syringe.

4. Infusion pump.

5. Pressure transducer for IBP monitoring.

6. Inj. Esmolol.

7. Inj. Dexmedetomidine.

\section{Study Methods}

All consented patients classified under ASA I were selected. They were randomly allocated using computer generated randomisation table into two groups, Group E and Group D. The randomisation sequence was prepared in double blinded manner. The study drug was prepared by the author.

The sample size was calculated to be 52 (we have taken 25 in each group) using OpenEpi software Version 3.01 taking into an account mean recovery characteristics, sedation scores (time to modified Aldrete score $>9$ mins.) of $9.4 \pm 2.5$ in dexmedetomidine and $7.5 \pm 2.3$ in esmolol group from the study done by Shams $\mathrm{T}$ et al; $95 \%$ confidence interval and $80 \%$ power.
All patients were advised overnight fasting. All patients were premedicated with Inj. Glycopyrrolate $4 \mathrm{mcg} / \mathrm{kg}$ intramuscularly 45 minutes before surgery. Inj. Midazolam $0.03 \mathrm{mg} / \mathrm{kg}$, Inj. Fentanyl $2 \mathrm{mcg} / \mathrm{kg}$ intravenously given before starting the arterial line under local anaesthesia. Monitors used were ECG, Pulse oximeter, ETC02, IBP. The arterial line was started with 20-G cannula under local anaesthesia. In Group E, patients were given a loading dose of Esmolol $0.5 \mathrm{mg} / \mathrm{kg}$ over $1 \mathrm{~min}$ followed by infusion of 0.3 $0.8 \mathrm{mg} / \mathrm{kg} / \mathrm{hour}$ before induction. Infusion dose was titrated to obtain a mean arterial pressure of 60 - $65 \mathrm{mmHg}$. In Group $\mathrm{D}$, patients were given a loading dose of Dexmedetomidine at $1 \mathrm{mcg} / \mathrm{kg}$ diluted in $50 \mathrm{~mL}$ of $0.9 \%$ saline over 10 minutes followed by infusion at the rate $0.3-0.8 \mathrm{mcg} / \mathrm{kg} / \mathrm{hour}$ before induction. The infusion dose was titrated to obtain a mean arterial pressure between $60-65 \mathrm{mmHg}$. Propofol was the induction agents used in all patients. After preoxygenation for 3 minutes, Propofol was administered in the dose of $1-2$ $\mathrm{mg} / \mathrm{kg}$ until the loss of verbal response. Induction dose of Propofol was recorded. Intubation was done following administration of Inj. Atracurium $0.5 \mathrm{mg} / \mathrm{kg}$ with appropriate sized Endotracheal Tubes. Anaesthesia was maintained with $60 \% \mathrm{~N}_{2} \mathrm{O} / \mathrm{O}_{2}$ mixture. All patients were placed in 15 degrees reverse Trendelenburg position and their nasal cavities were packed with Cottonoids, soaked with Epinephrine in a concentration of 1: 1,00,000. All the surgeries were performed by the same Surgeon, who was blinded to the agent used, so as to ensure consistency in estimating the quality of the surgical field. Infusion of the study drugs was stopped 10 minutes before the end of the surgery. Patients were extubated after reversal with Inj. Neostigmine and Inj. Glycopyrrolate.

\section{Observation}

In our study, the following parameters were observed.

1. Dose of propofol required for induction.

2. Heart Rate- before induction, after induction, at 15 minutes, at 30 minutes, at 45 minutes during surgery, 5 minutes after stoppage of infusion of study drug, 10 minutes after stoppage of infusion of study drug, at the end of surgery, after extubation.

3. Blood Pressure- before induction, after induction, at 15 minutes, at 30 minutes, at 45 minutes during surgery, 5 minutes after stoppage of infusion of study drug, 10 minutes after stoppage of infusion of study drug, at the end of surgery, after extubation.

4. Quality of the surgical field- It is assessed using average category scale.

- Average Category Scale Score 0- No bleeding.

- Score 1- Minimal bleeding, suctioning not required.

- Score 2- Minimal bleeding, suctioning occasionally required.

- Score 3- Minimal bleeding, repeated suctioning required.

- $\quad$ Score 4- Moderate bleeding, repeated suctioning required, bleeding obscures surgical field.

- $\quad$ Score 5- Severe bleeding, surgery not possible as bleeding completely obscures the surgical field.

5. Emergence Time- It is the time interval between stoppage of the anaesthetic drugs and eye-opening to oral commands. 
6. Post-Anaesthesia Recovery Score- It is assessed using Modified Aldrete Score-

1. Activity- Able to move voluntarily or on command four extremities- 2, two extremities- 1, no extremities- 0 .

2. Respiration- Able to breathe deeply and cough freely- 2, Dyspnoea, shallow or limited breathing- 1 , apnoea- 0 .

3. Circulation- Blood pressure within $20 \mathrm{mmHg}$ of preop level- 2, Blood pressure within $20-50 \mathrm{mmHg}$ of preop level- 1 , blood pressure $\pm 50 \mathrm{mmHg}$ of preop level- 0.

4. Consciousness- Fully Awake- 2, Arousable on command- 1, Unresponsive- 0 .

5. Oxygen saturation- Saturation more than 92\%- 2, needs oxygen to maintain saturation more than $90 \%-1$, Saturation less than $90 \%$ with oxygen- 0 . Total Score- 15; 9 or more points are required for recovery to be confirmed.

6. Time required to attain Modified Aldrete Score of more than 9 is recorded.

7. Sedation Score at 15,30 and 60 minutes after extubation is recorded.

\section{Sedation Score- Ramsay Sedation Score}

Score 1- Patient is anxious, agitated or restless or both, Score 2- Patient is cooperative, oriented and tranquil, Score 3Patient responds to commands only, Score 4- Patient exhibits brisk response to light, glabellar tap or loud auditory stimulus, Score 5- patient exhibits sluggish response to light, glabellar tap or loud auditory stimulus, Score 6- patient exhibits no response.

\section{Statistical Analysis}

The data was analysed by statistical software SPSS 17.0 and XLSTAT 2013. Student " $t$ " test was used to find the significance in continuous data between the two groups.

\section{RESULTS}

The two groups were comparable to age and weight. The mean age in Group E was $31.84 \pm 8.6$. The mean age in Group D was $33.08 \pm 7.3$. The mean weight in Group E was $57.04 \pm$ 9.74. The mean weight in Group D was $56 \pm 9.12$.

\begin{tabular}{|c|c|c|c|c|}
\hline $\begin{array}{c}\text { Patient } \\
\text { Characteristics }\end{array}$ & Group E & Group D & T value & P value \\
\hline Age in Years & $31.84 \pm 8.6$ & $33.08 \pm 7.3$ & 0.543 & 0.5 \\
\hline Weight & $57.04 \pm 9.7$ & $56 \pm 9.1$ & 0.389 & 0.38 \\
\hline \multicolumn{6}{|c|}{ Table 1. Age and Weight Distribution in Groups } \\
\hline
\end{tabular}

The induction dose of propofol was lower in Group D (1.2 +/- $0.1 \mathrm{mg} / \mathrm{kg})$ compared to Group E $(1.65+/-0.13 \mathrm{mg} / \mathrm{kg})$ (Table 1), which was statistically significant ( $\mathrm{p}$ value $<0.001$ ) Table 1.

\begin{tabular}{|c|c|c|c|}
\hline Group & $\begin{array}{c}\text { Mean Dose } \\
\mathbf{m g} / \mathbf{k g}\end{array}$ & T value & P value \\
\hline Group E & $1.65 \pm 0.13$ & 12.20 & 0.00 \\
\hline Group D & $1.24 \pm 0.10$ & & \multirow{2}{|c|}{ Table 2. Induction Dose of Propofol } \\
\hline \multicolumn{3}{|c|}{}
\end{tabular}

Comparison of emergence time showed statistically significant differences between two groups. Emergence time is significantly higher in Group D than Group E (P value < 0.001) (Table 2).

\begin{tabular}{|c|c|c|c|}
\hline Group & Mean & T value & P value \\
\hline Group D & $13.14 \pm 1.1$ & 15.57 & 0.00 \\
\hline Group E & $7.62 \pm 1.3$ & & \\
\hline \multicolumn{4}{|c|}{ Table 3. Emergence Time } \\
\hline
\end{tabular}

Heart rates were compared between two groups. There were no statistically significant difference in heart rates before induction, after intubation at 15 minutes, 30 minutes, 45 minutes during the surgery, at the end of surgery, but there was significant difference in heart rates 5 minutes after the stoppage of drug, 10 minutes after stoppage of drug, after extubation. The heart rates were higher in Group E than Group D (Graph 1).

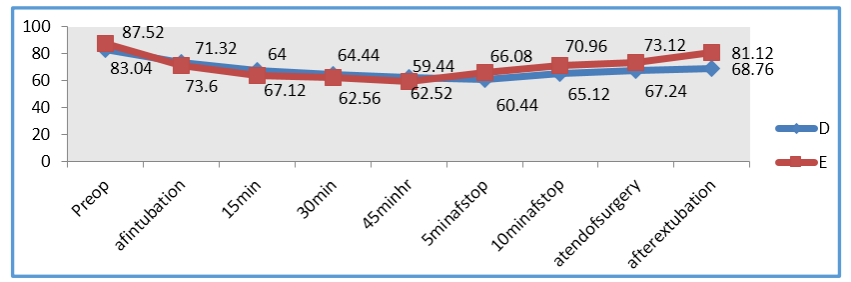

Graph 1. Heart Rate changes between Groups

Suvadeep et al (2013) studied the effects of intraoperative dexmedetomidine infusion on requirement of propofol for maintenance of optimum depth of anaesthesia during spine surgeries and concluded that dose of propofol was significantly reduced with the use of dexmedetomidine infusion. Heart rate and blood pressure at 5 minutes and 10 minutes after stoppage of infusion, at the end of surgery and after extubation were significantly lower in dexmedetomidine group than esmolol group. This was consistent with the results obtained by Malhotra et al (2013), studied the effects of dexmedetomidine on hypotensive anaesthesia in patients undergoing hypotensive anaesthesia and found that mean arterial pressure and heart rate was significantly lower with use of dexmedetomidine.

Systolic blood pressure and diastolic blood pressure were recorded. There were no statistically significant differences in both systolic and diastolic blood pressure in both the groups before induction at 15 minutes, 30 minutes, 45 minutes during the surgery, at the end of surgery, but there was significant difference in both systolic and diastolic blood pressure at 5 minutes after the stoppage of drug, 10 minutes after stoppage of drug, after extubation. Both systolic and diastolic pressure were higher in Group E than Group D. (Graph 2, 3).

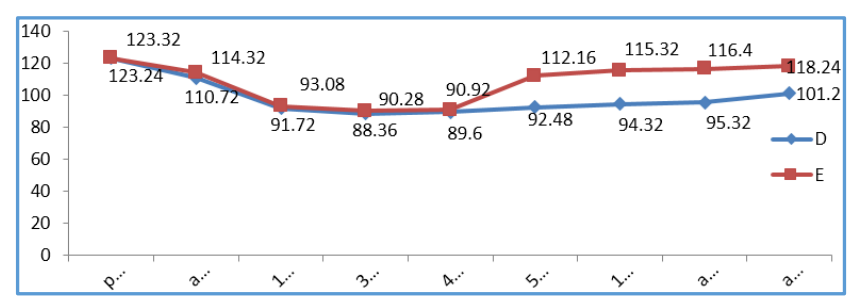

Graph 2. Systolic Blood Pressure changes between Groups 


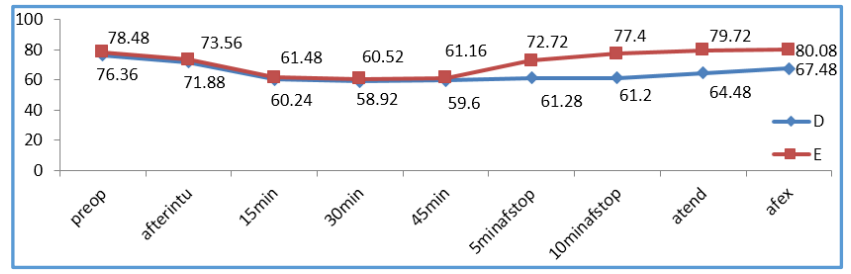

Graph 3. Diastolic Blood Pressure changes between Groups

Post anaesthesia recovery was significantly higher in Group D (15.4 \pm 1.84 minutes) than in Group E (10.86 \pm 0.97 minutes). Koi IO et al (2009) made a comparative study between esmolol and dexmedetomidine combined with desflurane for controlled hypotension during tympanoplasty in adults and found that esmolol group had shorter recovery time than dexmedetomidine group.

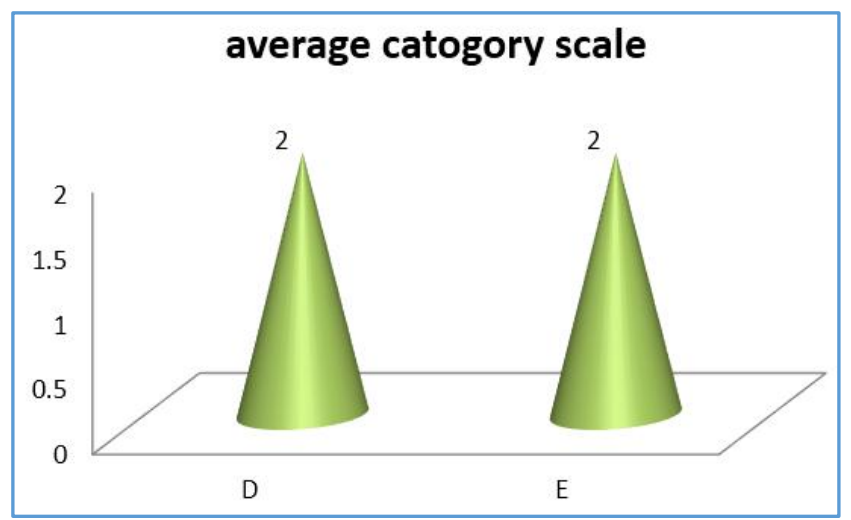

Graph 4. Quality of Surgical Field (Average Category Scale)

Comparison of quality of surgical field by average category scale showed no statistical difference between two groups. (Graph 4) Comparison of emergence time showed statistically significant differences between two groups.

\begin{tabular}{|c|c|c|c|}
\hline Group & Mean & T value & P value \\
\hline Group D & $15.4 \pm 1.8$ & 10.89 & 0.00 \\
\hline Group E & $10.86 \pm 0.9$ & & \\
\hline \multicolumn{3}{|c|}{ Table 4. Post Anaesthesia Recovery Score } \\
\hline
\end{tabular}

Comparison of post anaesthesia recovery score showed statistically significant differences between two groups in the time to achieve Modified Aldrete score of $\geq 9$. The time was significantly higher in Group D compared with Group E (P value $<0.001$ ) (Table 3 ). Comparison of sedation score using Ramsay sedation score between two groups showed that there was statistically significant differences in sedation scores at 15 minutes ( $p$ value $<0.001$ ) and 30 minutes (p value $=0.01$ ) after surgery. Sedation scores were significantly higher in Group D than Group E. There was no statistically significant difference in sedation score between two groups at 60 minutes after surgery (Graph 4).

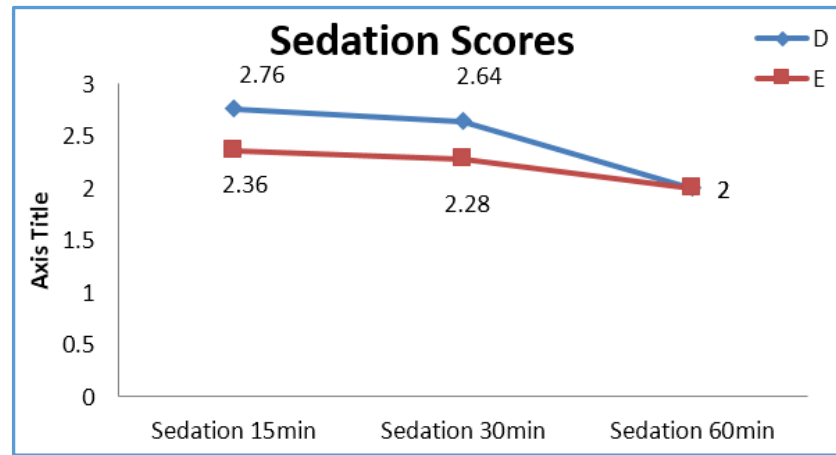

Graph 5. Sedation Score

\section{DISCUSSION}

The use of controlled hypotension in endoscopic sinus surgery has greatly reduced the blood loss and improved the visibility of surgical field. Many methods have been used for controlled hypotension. In our study, we assessed the effectiveness of using esmolol and dexmedetomidine. We found that the dose of propofol required for induction was significantly lower in dexmedetomidine group than esmolol group. 6

We found that both esmolol and dexmedetomidine were effective in producing a surgical field with improved visibility (average category scale $=2$ ). Farah Nasreen ${ }^{7}$ et al (2009) studied the effects of dexmedetomidine for patients undergoing middle ear surgery with hypotensive anaesthesia and found that the quality of surgical field was greatly improved with use of dexmedetomidine. Boezaart et al (1995) made a comparative study between sodium nitroprusside and esmolol using inducing hypotension in functional endoscopic sinus surgery and found that superior surgical conditions were seen with esmolol even with mild hypotension (MAP > $65 \mathrm{mmHg}$ ). Various studies have used dexmedetomidine in doses ranging from 0.5 to $10 \mathrm{~kg} / \mathrm{h}$ with not so much conclusive data associated with significant incidents of bradycardia and hypotension in higher doses. ${ }^{8}$ we found that the emergence time was significantly prolonged in dexmedetomidine group $(13.14 \pm 1.13$ minutes $)$ than esmolol group (7.62 \pm 1.36 minutes). Abdullah Aydin Ozcan et al (2012) made a comparative study between remifentanil and dexmedetomidine for controlled hypotension in patients undergoing endoscopic sinus surgery and found that recovery time was prolonged in dexmedetomidine group than remifentanil group. ${ }^{9}$ Turan et al (2007) made a comparative study between esmolol, remifentanil and dexmedetomidine in controlled hypotensive anaesthesia and found that post-extubation recovery score was longer in dexmedetomidine group than esmolol and remifentanil group. Sedation scores were higher in Group D than Group E at 15 mins. $(2.76 \pm 0.43$ vs $2.36 \pm 0.49)$ and 30 mins. ( $2.64 \pm 0.49$ vs $2.28 \pm 0.45)$ and there was no difference in sedation score between two groups at 60 minutes after surgery. CR Patel et al (2012) studied the effect of intravenous infusion of dexmedetomidine of on preoperative haemodynamic changes and post-operative recovery and found that post-operative sedation was significantly higher in dexmedetomidine group than control group. ${ }^{10}$ 


\section{CONCLUSION}

The observation of this study is that the use of dexmedetomidine for controlled hypotension for functional endoscopic sinus surgery has the additional advantage of sedative and anaesthetic sparing effect than esmolol apart from bloodless field. Surgical duration was found to be shorter with controlled hypotension. In FESS, controlled hypotension is a safe and effective technique as well as reduced operative bleeding and tachycardia was observed less. In comparison to Esmolol, dexmedetomidine provides consistent and effective pressure response. We conclude that single dose of Dexmedetomidine before GA induction was found to be effective to attenuate the haemodynamic response to intubation.

\section{REFERENCES}

[1] Gliklich RE, Metson R. The health impact of chronic sinusitis in patients seeking otolaryngologic care. Otolaryngology Head and neck surgery 1995;113(1):104-9.

[2] Srivastava U, Dupargude AB, Kumar D, et al. Controlled hypotension for endoscopic sinus surgery: comparison for esmolol and nitroglycerine. Indian J Orolaryngol Head and neck Surg 2013;65(Suppl 2):440-4.

[3] Chiruvella S, Donthu B, Siva JV, et al. Controlled hypotensive anaesthesia with dexmedetomidine for functional endoscopic sinus surgery: a prospective double blind randomized study. Journal of evaluation of Medical and dental sciences 2014;3(37):9556-63.
[4] Mengistu AM, Wolf MW, Boldt J, et al. Influence of controlled hypotension using esmolol and sodium nitroprusside on natriuretic peptides in patients undergoing endonasal sinus surgery. European Journal of anaesthesiology 2007;24(6):529-53.

[5] Guney A, Kaya FN, Yavascaoglu B, et al. Comparison of esmolol to nitroglycerine in controlling hypotension during nasal surgery. EAJM 2012;44(2):99-105.

[6] Grewal A. Dexmedetomidine: new avenues. J Anaestheiol Clin Pharmacol 2011;27(3):297-302.

[7] Celebi N, Artukoglu F, Dal D, et al. Effect of hypotensive anesthesia on cognitive function. A comparison of esmolol and remifentanil during tympanoplasty. Saudi Med J 2007;28(9):1357-61.

[8] Ramsay MA, Saha D, Hebeler RF. Tracheal resection in the morbidly obese patient: the role of dexmedetomidine. J Clin Anaesth 2006;18(6):452-4.

[9] Alagol A, Arar C, Kaya G, et al. Effect of dexmedetomidine and esmolol on haemodynamic response to tracheal intubation. Eur J Anaeasthesiol 2005;22:134-5.

[10] Keniya VM, Ladi S, Naphade R. Dexmedetomidine attenuates sympathoadrenal response to tracheal intubation and reduces perioperative anaesthetic requirement. Indian journal of anaesth 2011;55(4):352-7. 